\title{
(DES)CONSTRUÇÃO CORPORAL TRANS E O SABER BIOMÉDICO: REFLEXÕES SOBRE (IN)COMPREENSÕES, EQUÍVOCOS E SENTIDOS CORPORAIS
}

\author{
TRANS BODY (DE)CONSTRUCTION AND BIOMEDICAL KNOWLEDGE: \\ REFLECTIONS ON (MIS)UNDERSTANDINGS, MISTAKES, \\ AND BODY IMAGE
}

Daniella Chagas Mesquita ${ }^{1}$

Esmael Alves de Oliveira ${ }^{2}$

\section{RESUMO}

O artigo propõe, por meio do método cartográfico, uma análise das aproximações e distanciamentos que pessoas travestis e transsexuais fazem do saber biomédico ao produzirem estratégias para a construção de seus corpos. Foram discutidas quatro imagens-cena e duas conversas sobre experiências corporais trans, e uma entrevista realizada em um ambulatório transexualizador localizado numa capital de médio porte do centro oeste brasileiro. Constata-se que o saber biomédico continua a operar pela via da normalização e disciplinamento de corpos e sujeitos cujas identidades de gênero e corporalidades questionam o regime cisheteronormativo. Por outro lado (e ao mesmo), a existência e resistência de corpos e subjetividades plásticas e dissidentes que encontram no aparato biomédico apenas uma das múltiplas possibilidades disponíveis para a construção de seus corpos (trans)bordantes. Mais do que analisar as tecnologias ofertadas pela hegemonia (bio)médica, nos interessa analisar os arranjos micropolíticos traçados pelas pessoas em suas biocartografias.

Palavras-chaves: Corpo; Trans; Dissidências; Mato Grosso do Sul.

\begin{abstract}
This article uses the cartographic method to analyze the uses of medication and biomedical knowledge by the transvestite and transgender population to modify their bodies. The study encompasses four events and two conversations about trans experiences with their bodies and an interview at a hospital in a mid-sized capital in central-western Brazil. It is evident that biomedical knowledge still establishes cis-heteronormative patterns regarding body questions, although non-conforming gender identities challenge them. Moreover, these dissonant bodies consider the medical interventions only one of the several possibilities to adapt their bodies. The authors preferred to analyze the micro political arrangements outlined by the subjects in their (bio) cartographies rather than the hegemonic technologies offered by the healthcare system.
\end{abstract}

\footnotetext{
1 Atualmente é doutoranda no Programa de Pós-Graduação em Antropologia e Arqueologia da Universidade Federal do Paraná (PPGAA/UFPR). Mestra em Antropologia Social pelo Programa de Pós-graduação em Antropologia Social da Universidade Federal de Mato Grosso do Sul (PPGAS/UFMS). Graduada em Psicologia pela Universidade Católica Dom Bosco (2018). e-mail: daniellacmesquitaf@hotmail.com

2 Atualmente é Professor na Faculdade de Ciências Humanas da Universidade Federal da Grande Dourados (FCH/UFGD) e no Programa de Pós-graduação em Antropologia da Universidade Federal da Grande Dourados (PPGANT/UFGD). Doutor em Antropologia Social (PPGAS/UFSC). e-mail: esmael_oliveira@live.com
} 
Keywords: Body; Trans; Queer; Mato Grosso do Sul. INTRODUÇÃO

\begin{abstract}
A pele é orgânica, mas, sob os fartos seios, próteses de silicone: a negação de uma condição natural. A busca por aceitação em uma instância governada por seres que sempre estiveram em declínio (VIEIRA, 2017, p. 86).
\end{abstract}

Para experimentar as reflexões que aqui se seguem acerca da corporalidade trans, partimos de dois pontos que se interconectam rizomaticamente, que se aproximam e que produzem linhas de fuga diversas: a ideia do escritor e editor campograndense, Leonardo Triandopolis Vieira (2017), que em um de seus livros traz a ideia de pedaços humanos, dos quais somos todos feitos, e a terminologia construcción corporal trans adotada por Anahí Farji Neer (2017) para pensar a reconfiguração do papel da psicologia nos tratamentos ofertados às pessoas trans na Argentina.

Em meio as poesias de Vieira (2017) e a etnografia de Neer (2017), o corpo humano deixa de lado os arranjos deterministas dos órgãos (que frequentemente fazem com que sejamos lidos a partir de uma anatomia no qual pênis e vagina erigem-se como "verdades" inquestionáveis), e passa a ser pensado como um conjunto instável e precário, cujos "pedaços" que podemos negociar, remanejar, inserir ou retirar, e nestes movimentos, experimentar uma construção corporal singular.

Acreditamos que os atravessamentos entre estes dois pontos (e tantos outros) são interessantes para pensarmos as corporalidades trans, (re)configurando um campo potente para escaparmos da ideia de uma "redesignação" ou "readequação" sexual (termos comumente utilizados pelo campo biomédico e psi para se referir ao processo de "mudança de sexo" das pessoas trans e que teria como pressuposto a adequação a padrões binários impostos ao gênero). O abandono destas amarras binárias, nos permitem ao contrário, pensar em uma construção de um novo corpo, que não necessariamente se adeque aos padrões estabelecidos, mas que possa tensionar ao que outrora foi imposto, e construir para si um corpo próprio.

Acerca do processo de docilização dos corpos, Foucault (1999b) afirma que é durante a época clássica que o corpo é descoberto como alvo e objeto de poder e, no século XVIII, o 
poder designa limitações, proibições e obrigações ao corpo, impondo docilidade e utilidade a este através do disciplinamento dos corpos, que em uma maquinaria de poder, esquadrinha, desarticula e recompõe o corpo. Para o autor, neste contexto disciplinar nasce "um espaço útil do ponto de vista médico" (FOUCAULT, 1999b, p. 124).

Assim sendo, analisaremos neste artigo algumas estratégias e dispositivos agenciados por pessoas travestis e trans em seus encontros com a biomedicina a partir dos procedimentos interventivos. Para tal, apesar de reconhecer a importância de atributos como cabelo, roupa, maquiagem para a construção da corporalidade trans, entre outros (BENEDETTI, 2000), em um primeiro momento focaremos nas discussões sobre as intervenções que teoricamente são mais dependentes do poder biomédico, envolvendo procedimentos cirúrgicos e de hormonioterapia.

Posteriormente, analisaremos as linhas de fuga engendradas por pessoas travestis, transexuais e não-binárias em suas experiências corporais, pensando alguns afastamentos com relação ao saber-poder biomédico. Sob os traços destas linhas de fuga, a proposta de Deleuze e Guattari (1996) de um corpo sem órgãos (CsO), que se opõe à organização imposta pelo organismo, abrindo o corpo à conexões, distribuição de intensidades e desterritorializações, nos parece oportuno para pensarmos formas alternativas de um cuidado de si e de experimentações corporais que subvertem os ditames dicotômicos historicamente produzidos e socialmente impostos sobre o corpo das pessoas travestis e trans.

Nestas subversões produzidas pelas linhas de fuga, dá-se espaço para vidas e corpos coloridos, que transbordam as dicotomias cisheteronormativas e, dessa forma, adquirem sentidos inúmeros. Tais sentidos criativos e contestadores são aqui apresentados a partir de algumas ilustrações de autoria de Lune Carvalho, artista trans masc nonbinary (como se autodefine em seu Instagram @1unecornio), que a partir de uma perspectiva Queer, dá corpo ao que escapa aos regimes normativos. ${ }^{3}$

\footnotetext{
3 Vale ressaltar que mantivemos as legendas originais das ilustrações aqui apresentadas, respeitando os significados a elas atribuídas por Lune.
} 


\section{LINHAS EXPERIMENTAIS}

A partir das provocações de Deleuze e Guattari (1996), que afirmam que a esquizoanálise (prática-teoria por eles inaugurada) incide apenas em linhamentos e na análise do desejo, questionando que linhas traçamos, remanejamos, interrompemos, prolongamos ou retomamos, propomos aqui que a análise das relações, aproximações e distanciamentos entre a construção corporal trans e o saber biomédico, se dê a partir das noções de experimentação e cartografia de linhas. Para isso, tomamos como foco quatro imagens-cena, duas conversas entre amigas e uma entrevista.

\subsection{Imagem-cena 1: a mastectomia coagida}

Maio de 2019, IV SIGESEX - Gêneros, sexualidades e conservadorismos: a política dos corpos, os sujeitos e a disputa pela hegemonia dos sentidos culturais, realizado na Universidade Federal do Mato Grosso do Sul (UFMS). Ao final de uma mesa redonda, o microfone é aberto para perguntas, da plateia uma pessoa pede a fala. Neste momento a pergunta dá lugar a uma performance-desabafo: um homem trans, segurando o microfone e relatando sua dor, tira a blusa, desabotoa botão por botão sua roupa pós-cirúrgica, e posteriomente joga-a no chão.

Segundo ele, foi o primeiro homem trans a realizar a mastectomia no Mato Grosso do Sul. Seu corpo ainda cicatrizava e doía. Ao contrário do que se possa imaginar, seu procedimento cirúrgico não foi demandado por ele em decorrência de um desejo. Não, não era sua vontade fazê-lo. Escolheu o procedimento cirúrgico de retirada das mamas, com recuperação lenta e dolorosa, para que fosse aceito e reconhecido como homem, reconhecimento social este que, segundo ele, era negado pela permanência em corpo de seus seios "femininos".

Na plateia, todos absortos diante de seus relatos. Ali era compartilhado suas dores, dores essas causadas por uma imposta e coagiada adequação sexual de seu corpo que, para acessar o 
"passaporte" da inteligibilidade cisheteronormativa e seu consequente reconhecimento no mundo social, precisava mutilar-se a si mesmo.

\subsection{Imagem-cena 2: "volte quando você estiver completo"}

Série Queer Eye - reality show produzido pela plataforma Netflix - temporada 2, episódio 5: O céu é o limite. O episódio começa com cenas de uma mastectomia. Skyler conta: "eu nasci e me identificava como mulher. Mas desde que estava na pré-escola, eu sabia que não era eu. Me lembro de ter 12 anos, na frente do espelho e contorcendo meu corpo para ser mais masculina. Pensando: "Vou fazer uma cirurgia que me faça parecer assim"”. Logo após a cirurgia, perguntam se ele deseja ver o resultado, ainda anestesiado e não plenamente consciente Skyler olha para baixo, vê pela primeira vez seu novo corpo, chora de emoção.

$\mathrm{Na}$ metade do episódio, um dos apresentadores acompanha Skyler para mudar seu marcador de gênero na carteira de habilitação, momento em que Skyler conta que na verdade ele já havia tentado fazer esta alteração antes, mas não foi autorizado: "Eles não mudaram, foram inflexíveis sobre precisar ter uma carta da cirurgia. Aí uma mulher me disse algo parecido com: "Não vou fazer isso, volte quando você estiver completo".

Para o departamento de trânsito da cidade de Skyler, não importava sua autoafirmação enquanto homem trans, nem mesmo suas vestimentas masculinas e sua barba, ele só teria seu marcador de gênero alterado em sua habilitação quando estivesse "completo", condição esta que dependeria de um procedimento cirúrgico para a retirada de seus seios (a ausência deste, segundo a lógica cisheternormativa, seria um "atestado" de sua masculinidade).

\subsection{Imagem-cena 3: não mais esconder}

Um homem trans posta nas redes sociais uma foto sem camisa com a seguinte legenda: "Sou homem, um homem com seios, seios que me incomodam, seios que me causam uma disforia absurda. Dias eu convivo bem, dias nem tanto. Seios que caíram, mas infelizmente ainda não sumiram... Já que estão em meu corpo, são meus e não me tirarão a liberdade de 
postar uma foto sem camisa, de sentir o vento bater, de sentir a brisa... I'm free”. A foto foi denunciada na rede social Facebook, censura do que se escolheu não mais esconder.

\subsection{Imagem-cena 4: "não ter silicone não me faz menos mulher hoje"}

Dia 6 de dezembro de 2019, Miss Trans/Travesti Mato Grosso do Sul 2019. Durante os desfiles das candidatas, duas em especial se destacam: uma candidata do interior (CorumbáMS) e a outra da capital (Campo Grande-MS). A Miss Corumbá tem seu corpo todo desenhado e esculpido, curvas e silicone. A Miss Campo Grande, segundo ela mesma narrou em outro evento, passou a entender-se como mulher trans a pouco tempo, após receber o prêmio Miss Gay 2018, seu corpo ainda não se adequava ao estereótipo do corpo feminino, apesar de traços faciais delicados.

Ao final, ambas candidatas disputavam o prêmio de primeiro lugar. Da plateia os espectadores gritam “Corumbá! Corumbá! Já ganhou!”, mas o veredito dos jurados era outro, a candidata de Campo Grande ganha o título de Miss Trans/Travesti Mato Grosso do Sul 2019, ajoelha no chão e chora, depois levanta-se e ainda emocionada agradece o apoio dos pais e afirma: "não ter silicone não me faz menos mulher hoje".

No dia seguinte a organização do evento emite uma "Nota Pública de Esclarecimentos sobre o Miss Trans/Travesti MS - 2019 e Miss Plus Trans/Travesti MS- 2019”, em que destacamos o pequeno trecho a seguir:

É preciso esclarecer que ser Trans/Travesti, não é encher o corpo de silicone, plásticas e/ou hormônio como muitas pessoas pensam. Ser travesti/transexual, está muito mais alinhado com o ser feminina, com o que está no psicológico, no papel social assumido diuturnamente - (sendo quem realmente você é), - do que encher o corpo de hormônio, plásticas e silicone!

É importante ressaltar, que se assim for, então qualquer mulher ou homem CISgênero que fizer aplicação de qualquer substância do tipo, poderão serem chamadas/os de TraveTraestisnsexuais. O que não condiz com a realidade! (sic).

\subsection{Conversa 1: a troca de hormônios}


Dia 9 de novembro de 2019, sexta-feira. No intervalo da aula do mestrado sobre interseccionalidades e marcadores sociais da diferença, conversando com Ariel Dorneles dos Santos ${ }^{4}$, é comentado como seus seios cresceram rapidamente. Ao ser indagada sobre o que fizera para tal resultado, Ariel afirma: "Troquei de hormônio. Este novo é pior para minha saúde, mas apresenta resultados mais rápidos. Eu estava cansada de esperar"

\subsection{Conversa 2: erro de pronomes}

Dia 7 de dezembro de 2019, sábado. Eu, Daniella, estava na Feira Vegana de Campo Grande - MS e volto a encontrar-me com Ariel, agora acompanhada por uma pessoa amiga. A noite um forte incômodo toma conta de mim, resultado da confusão ocorrida no referido encontro em que continuamente erro os pronomes de tratamento ao referir-me à amiga de Ariel ora no masculino ora no feminino. Apesar de inserida nos estudos e discussões acerca de gêneros e dissidências, o mal-estar gerado pela confusão permitia pensar como somos capturados pela busca da ordem, da coerência, das definições.

Em cena, minha confusão diante de um corpo que, embora masculino, apresentava seios ao mesmo tempo em que em seu rosto era possível deparar-se com uma linda e volumosa barba. Algumas dúvidas logo vieram à minha cabeça: Identificava-se como homem trans, mas não havia realizado mastectomia? E se sim, por que Ariel a chamaria no feminino? Ou identificavase como mulher trans, tomando hormônios ou fazendo uso de silicones para aumento dos seios, mas mantinha há tanto tempo e com tanto cuidado a barba? Dez dias depois, ao conversar com Ariel sobre tais confusões e incomodada por ter errado o pronome de tratamento, Ariel revela que sua amiga se identificava como uma pessoa não-binária, mas que preferia ser chamada no feminino.

\subsection{Entrevista 1: sobre o ambulatório transexualizador}

\footnotetext{
${ }^{4}$ Travesti, jornalista e cientista social de formação, mestranda em Antropologia Social na Universidade Federal de Mato Grosso do Sul - sua pesquisa de mestrado versa sobre a sociabilidade trans em Campo Grande.
} 


\section{Debates Insubmissos}

Revista

Dia 21 de dezembro de 2019, entrevista realizada com um dos responsáveis pelo ambulatório transexualizador do Hospital Universitário da UFMS, aberto desde janeiro de 2017. Atualmente o ambulatório oferece gratuitamente os seguintes serviços: acolhimento, testagem rápida para infecções sexualmente transmissíveis, assistência social, atendimento psicológico e médico. A hormonioterapia feminina é realizada com acompanhamento de ginecologista e a masculina por urologista. Após dois anos de acompanhamento, as pessoas que desejarem e que atenderem aos critérios de avaliação, são encaminhadas para cirurgia.

No referente a processos cirúrgicos, o entrevistado estima que praticamente $100 \%$ dos homens transsexuais demandam a mastectomia, enquanto apenas 1/3 solicita cirurgia de redesignação sexual; já as mulheres transsexuais $70 \%$ solicita a redesignação e menos da metade das travestis demanda o mesmo. Acrescenta ainda o fato de que, em teoria, o Sistema Único de Saúde (SUS) não banca os custos do silicone, e que "a maioria das pacientes consegue ganhar mama com a hormonioterapia".

Pesquisadora: E você acha que o desenvolvimento da mama é uma das questões centrais na hormonioterapia ou não?

Interlocutor: Sim, porque assim, elas desejam um corpo feminino, e poucas partes do corpo são mais evidentemente femininas do que a mama. Porque assim, o cabelo, por exemplo, é uma coisa que se qualquer pessoa deixar crescer e tratar fica do jeito que for, pode ficar com um aspecto feminino ou masculino, não precisa de uma coisa tipo assim cirurgia, remédio, mas agora a mama é o que evidencia mesmo. E assim, mas aí é um dado da USP, de quando a gente foi visitar eles, eles falaram que mais de $90 \%$ ficam satisfeitíssimas com a hormonioterapia, algumas poucas não tinham desenvolvimento nenhum, daí eles propunham cirurgia, que lá eles fazem.

Pesquisadora: Pensando a construção de um corpo trans, que questões você acha que são mais importantes, e que a medicina consegue dar maior suporte nessa construção de um corpo trans? 


\section{Debates Insubmissos}

Revista

Interlocutor: O trabalho com o hormônio. Ele faz uma coisa assim, até estranho você ver como que muda da água pro vinho e eu acho que a grande questão aí primeiro a pessoa se sentir feliz com ela mesma, ela consegue através da hormonioterapia, mas em termos de... como eu vou falar assim, de saúde pública, o que eu penso é, com a hormonioterapia a pessoa consegue passar sem visível dentro das outras, dentro dos das outras pessoas cis (sic).

Pesquisadora: Consegue o que?

Interlocutor: Ela ser mais invisível.

Pesquisadora: Tá falando da passabilidade?

Interlocutor: De diminuição de violência, de agressão, então assim, por que com a hormonioterapia, em seis meses, um pouquinho mais, uma mulher trans realmente parece uma mulher cis, e um homem trans realmente parece um homem cis, então assim a menos que a pessoa fale, os outros não conseguem ver, e isso tira essas pessoas daquele grau de violência por... não é homofobia... enfim

Pesquisadora: Transfobia.

Interlocutor: Transfobia, isso. Tá, então aí eu, para mim, saúde pública é a principal incluindo hormonioterapia. É claro que elas não vêm só por conta disso, é para se sentir satisfeita com o próprio corpo, então consegue ter as duas coisas, então ganho psicológico e diminuição de uma vulnerabilidade social, então isso só com hormônio a gente já faz bastante isso, já dá para ver bastante isso daí. É claro que assim, as mulheres que começaram a hormonioterapia bem mais cedo, ali perto da adolescência, elas têm um resultado estético muito maior, agora os homens trans não, na hora que começou tomar testosterona dá cabo do negócio e faz mesmo, muda voz [trecho incompreensível]. E aí então, por exemplo, o hormônio feminino ele não consegue tirar o que a testosterona já fez ao longo da vida, né, então pomo de adão não volta, a voz não fica mais fina, então alguns ganhos a gente não consegue, por isso que o ideal começar mais cedo, só que o começar mais cedo a gente entra ai: ah mas é adolescente! Vai ter condição de tomar uma decisão dessa? Então é coisa que se discute muito. 


\section{Debates Insubmissos}

Revista

Pesquisadora: Entendo. E alguma outra questão que você acha que a medicina contribui bastante na construção do corpo trans além do hormônio?

Interlocutor: As cirurgias avançaram bastante né, então se você pegar uma foto de uma genitália feminina trans, é bem próximo do de nascimento, né. A genitália masculina ela ainda não tá assim, o procedimento cirúrgico não é tão bom quanto, o resultado final né não é tão bom quanto da genitália feminina, mas assim, é uma mudança, não sei, é até difícil de... Você tem uma mudança praticamente completa de um corpo, desde genitália, desde mamas que podem ou não complementar [trecho incompreensível]. Mas a hormonioterapia já faz também uma redistribuição de gordura no corpo, ela dá o formato de uma pessoa com o gênero com o qual ela deseja, então só isso eu já acho que é um negócio grande, mas eu acho o principal é... Parte do que você fala de, como que fala, que você falou, de construção do corpo trans, então eu vejo a ajuda médica muito mais como um invólucro né, a gente vai mexer na casca da pessoa, então a grande questão, das outras questões internas, a gente não consegue mexer só com a hormonioterapia, a gente mexe no sentido assim, ela vai ficar mais feliz, então ela tende a ter mais facilidade de sair da depressão, mas é... [trecho incompreensível] A chance de depressão, então com isso a gente precisa muito do apoio da psicologia, que é uma coisa que não tem como mexer, é claro, tem medicação pra depressão, ok, eu vou tirar essa pessoa do basal depressivo dela e colocar ela um pouquinho mais acima, mas são construções que ela precisa trabalhar. E é engraçado que às vezes têm alguns pacientes que, não é que transita mal, mas é que assim, às vezes eles também têm essa transição psicológica conforme vão fazendo essa transição hormonal, transição física né. [...] Por exemplo, teve coisas bem interessantes que eu aprendi aqui com elas né, na primeira vez, tava atendendo um homem trans, sem nada de hormônio, primeira vez pra tomar, então chegou uma mulher com roupas masculinas, ponto né. Aí o residente falando "porque ela", "porque ela" [...] e aí eu falei: não, é ele, tem que tratar pelo o que a pessoa deseja, nome social, papapa. Daí ela falou assim: não, doutor, eu que pedi pra chamar de ela, porque eu olho no espelho [trecho incompreensível]. [grifo nosso]

Pesquisadora: Por que o que? 


\section{Debates Insubmissos}

Revista

Interlocutor: Ela, eu me olho no espelho e ainda sou uma mulher, então não consigo ainda ouvir Paulo, Pedro, João, enfim... não consigo ainda ouvir meu nome masculino, um dia, quando meu eu masculino nascer de verdade, quando eu tiver transicionando, ai eu vou falar para vocês me chamarem de ele. Então foi aí que eu parti pra ver que assim, que a construção psicológica, não é que que ela, ela se sente um homem, então essa pessoa sente um homem, mas não é por conta disso que ela já se definiu totalmente como homem, porque o corpo precisa acompanhar pra o crescimento psicológico dá o formato final que ele quer, mas é que o corpo tá de um jeito, e a percepção do outro ela também não consegue organizar, ela tem difículdade.

\section{[grifo nosso]}

Pesquisadora: A gente têm falado muito da hormonioterapia e a gente sabe também que muitos medicamentos tão aí disponíveis e que tem como comprar sem passar necessariamente pelo médico, por exemplo, anticoncepcional, qualquer farmácia você compra.

Interlocutor: Por essa forma algumas delas já vem usando hormônio desde a adolescência, porque o anticoncepcional é muito fácil de achar, o difícil é testosterona, a testosterona, é, assim, até pra prescrever, não aceita uma via só, tem que pôr o seu CPF, CID, é uma enjoeira, então é difícil de prescrever, mas o anticoncepcional qualquer um vai comprar, e inclusive, por exemplo, se você tem, se... mesmo se a mulher trans né, nunca usou, tem a cara masculina ainda, uma amiga dela pode comprar um anticoncepcional, falando que é pra si mesma, é muito fácil.

Pesquisadora: E o que você pensa sobre isso?

Interlocutor: Bom, de certo modo, um lado mais ou menos que você dá pra pensar em redução de danos, até danos psicológicos, é que essa pessoa às vezes consegue fazer isso desde muito cedo, não precisa esperar os 18 anos que tá colocado na lei, mas o maior problema disso é que na maioria das vezes usam errado e usam superdosagem, se usassem a dosagem normal, igual a qualquer mulher usando para anticoncepcional, a gente tem uma chance menor de ter problema, mas eu já vi aqui mulher que tava usando a cartela de anticoncepcional junto com a injeção, junto com o outro lá, uns dois, três anticoncepcionais ao mesmo tempo juntos, fazendo superdosagem. Como uma outra que veio aqui só uma vez, essa realmente era usuária de droga 
pesada, tinha várias questões, e tomou uma cartela inteira de anticoncepcional em um dia só, então tem uma chance de ter o pior evento que eu posso ter com o uso do anticoncepcional, que é trombose, trombose é um entupimento dos vasos do corpo, na maioria das vezes dá na perna, mas pode dar no cérebro, embolia pulmonar. Os riscos de... morte. Isso é principalmente para o hormônio feminino, com o hormônio masculino isso não tem tanto.

Pesquisadora: [...] na concepção que eu tenho, pelos amigos trans e pelas amigas trans, travestis, que tenho, me parece que o seio é mais importante do que o órgão genital, na construção de um corpo trans, então assim, é tomar o hormônio, colocar o silicone, mesmo que continue com pênis, é tirar os seios, mesmo que continue com a vagina.

Interlocutor: O que eu vejo muito, é... é porque a representação social da feminilidade, então tá exposto, o genital a gente esconde, seja ele masculino ou feminino, a gente esconde muito bem na roupa, mas o seio não, ele salta na roupa, tanto para mais, quanto para menos, que o homem trans ele quer esconder essa aparência, enquanto a mulher trans quer que essa aparência brote, cresça, então é assim o que as pessoas vêm, o que chama atenção. Mas uma coisa também, já que você falou até sobre o programa e tudo mais, um ponto que eu não abordei e que é importante, era sobre o uso do silicone industrial. A gente tem poucas pacientes aqui, mas sim, travestis que são, ou que já são ou que já foram em algum momento garotas de programa, e aí uma das coisas que elas falam, mesmo que elas não queiram ter um peito grande, o que chama a atenção justamente para a profissão né de garota de programa, é ter seios grandes, então na pressa de conseguir isso, porque realmente pelo silicone é muito mais difícil conseguir, e o próprio hormônio às vezes demora conseguir o tamanho desejado, às vezes elas recorrem às bombadeiras pra poder fazer o uso do silicone industrial, e esse sim é outra catástrofe, né? Além de deformar o corpo, ele pode migrar do local, ou então às vezes cair, tem mulheres que colocam na perna, silicone vai parar lá no tornozelo, porque assim tem deformidade por efeito da gravidade ao longo do tempo, além de que na hora de colocar, pode infeccionar, pode pegar um vaso aquele silicone parar, fazer a mesma coisa da trombose, só que aí vai fazer uma embolia com um óleo, então ele entope o coração, o cérebro, pulmão do mesmo jeito, então é uma questão meio complicada também. 


\section{3. (DES)PENSAÇÕES INDISCIPLINADAS}

A diferença sexual é uma heterodivisão do corpo, marcada por práticas discursivas constantemente reiteradas, para qual o "sexo" funciona não somente como norma, mas como parte de uma prática regulatória de simetria impossível, que produz os corpos que governa, como um texto socialmente construído, cria a materialidade dos corpos, divide-o e fragmentao em órgãos e materializa a diferença sexual no corpo, a serviço da cisheteronormatividade (BUTLER, 2014; PRECIADO, 2019).

Deste modo, o "sexo" não é o que alguém tem, nem uma descrição estática do que alguém é, mas uma das normas que torna alguém viável, que lhe confere inteligibilidade, corpo e identidade, configurando-se, assim, como uma norma cultural que governa a materialização dos corpos e não como um dado corporal e natural em si mesmo (BUTLER, 2014; FOUCAULT, 1999a).

Para Guattari e Rolnik (2013), a diferenciação é encontrada em nossas sociedades nas teorias relativas ao falo, ou seja, as teorias ocidentais em sua maioria separam os sexos em uma diferenciação binária sob uma perspectiva falocêntrica. Somos segmentarizados em oposições duais: os homens e as mulheres, de forma que o imperativo heterossexual possibilita ou impede certas identificações, em uma matriz excludente, que produz simultaneamente seres abjetos (BUTLER, 2014; GUATTARI; ROLNIK, 2013).

A relação entre a diferença sexual e o corpo é tão intensa que Paul Preciado (2019, p. 416), discordando da ideia performática de Judith Butler, afirma que o gênero é protético, "não se dá senão na materialidade dos corpos. É puramente construído e ao mesmo tempo inteiramente orgânico. [...] O gênero se parece com o dildo". Para o autor, este poderia ser resultante de uma tecnologia sofisticada de fabricação de corpos sexuais.

Nesse mesmo movimento de questionamento de uma pretensa ordem "natural", Donna Haraway (2009) fala em termos de um corpo ciborgue. Assim, em uma sociedade cada vez mais baseada e sustentada pelas novas tecnologias, por circuitos, hardwares, nanotecnologias, suplementos alimentares, anabolizantes, vacinas, psicofármacos etc, os limites entre o "natural" 
e o "artificial” mostram-se cada vez mais insustentáveis. É assim que se erigem corpos híbridos que, ao utilizarem algum tipo de prótese corporal (silicones, pernas ou braços protéticos etc), questionam a pretensa ordem "natural" das coisas e dos corpos. Não mais meros silicones, mas "meus seios", não mais próteses mecânicas, mas "minhas mãos, braços e pernas".

Tomaz Tadeu (2009), na apresentação que faz do "Manifesto", indaga: Afinal, “onde termina o humano e onde começa a máquina? [...] onde termina a máquina e onde começa o humano?" (TADEU, 2009, p. 10). Parafraseando o autor, ousamos também indagar a partir dos corpos trans: Onde começa e onde termina minha masculinidade e minha feminilidade? Que peito ou que pau é esse que não tem a última palavra sobre meu corpo, meu gênero e meu desejo?

Assim, a partir da experiência de uma corporalidade plástica, pessoas travestis e trans questionam noções ontológicas de corpo e de identidade. Produzindo sua "carne", colocando ou retirando mamas, produzindo uma vagina ou um pênis (ou mesmo deixando-as como estão), constituindo deliberadamente uma androgenia não binária que questiona as normas de gênero, erige para sim um corpo-ciborgue que "nos força a pensar não em termos de "sujeitos", de mônadas, de átomos ou indivíduos, mas em termos de fluxos e intensidades" (TADEU, 2009, p. 14).

Não podemos ignorar que nossos corpos forjados sob a égide de uma identidade ontológica, de uma cisgeneridade dicotômica, de uma coerência aparentemente instransponível, mais que "natural", é antes resultado de uma longa produção de um saber-poder no tempo. Sobre isso nos alerta Michel Foucault (1999a). De acordo o autor, "as disciplinas do corpo e as regulações da população constituem os dois pólos em torno dos quais se desenvolveu a organização do poder sobre a vida" (FOUCAULT, 1999a, p. 131), e mais do que o corpo, através de mudanças do capitalismo, o "sexo", "gênero", "sexualidade", "identidade sexual" e “prazer” são transformados em objetos de gestão política da vida (PRECIADO, 2018).

Para Preciado (2018), a ciência (principalmente a psicologia, sexologia e endocrinologia) só alcançou hegemonia discursiva e prática em nossa cultura em decorrência de seu funcionamento como aparato discursivo-material de produção físico-corpórea. $\mathrm{O}$ 
prestígio do saber e da prática médica remetem a "uma tradição que remonta a muito longe na cultura grega, o cuidado de si está em correlação estreita com o pensamento e prática médica" (FOUCAULT, 1985, p. 59). Este cuidado de si, gerador de uma arte de viver, é resultante de uma cultura de si, para qual, "o aumento do cuidado médico foi claramente traduzido por uma certa forma, ao mesmo tempo particular e intensa, de atenção com o corpo" (FOUCAULT, 1985, p.61).

No século XVIII, os médicos tornam-se especialistas e administradores do espaço público, sua administração governamentalizada foi uma das grandes herdeiras do pastorado, propondo-se a conduzir condutas. Todavia, estas práticas de condução de condutas não se dão pela via da repressão, mas por meio de diferentes estratégias de controle-estimulação. O poder é forte porque é produtivo, fabrica corpos, corpos dóceis e submissos (FOUCAULT, 1999b; $2008 ; 2015)$.

Tudo o que é do domínio da ruptura, da surpresa e da angústia, mas também do desejo, da vontade de amar e de criar, deve se encaixar de algum jeito nos registros de referências dominantes. Há sempre um arranjo que tenta prever tudo o que possa ser da natureza de uma dissidência do pensamento e do desejo. Há uma tentativa de eliminar aquilo que eu chamo de processos de singularização. Tudo o que surpreende, ainda que levemente, deve ser classificável em alguma zona de enquadramento de referenciação (GUATTARI; ROLNIK, 2013, p. 52).

Assim, o poder ao invés de proibir, reprimir ou barrar, busca regular, governar e conduzir corpos e almas e conter as dissidências. Isso implica uma tentativa constante de normalização. É como se o dispositivo normalizador dissesse: “Quer ser uma pessoa trans? Tudo bem, mas tem que ser de uma determinada forma, para ser homem deve retirar os seios, deixar a barba crescer, cortar os cabelos; para ser mulher precisa retirar o pênis, colocar silicone, fazer megahair, fazer as unhas. Deve escolher entre ser homem ou mulher. Meninos vestem azul e meninas vestem rosa ${ }^{5}$. Se você se adequar ao meu padrão cisheteronormativo, eu te autorizo a transição".

Nesse enquadre, vale lembrar como o dispositivo biomédico tem historicamente operado como uma engrenagem produtora de uma vontade de "verdade" (LEITE JR, 2011).

\footnotetext{
${ }^{5}$ Como dito e reiterado várias vezes pela responsável pelo ministério da Mulher, da Família e dos Direitos Humanos, do atual governo Bolsonaro, a pastora Damares Alves.
} 


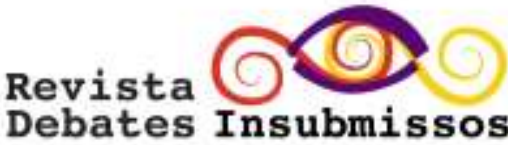

Não por acaso a nova resolução do Conselho Federal de Medicina (Resolução n ${ }^{0}$ 2.265/2019) que regula as intervenções em torno das transições de gênero. Dentre as reiterações do dispositivo disciplinar, a reiteração do regime pastoral: "o atendimento médico deve contar com anamnese, exame físico e psíquico completos". ${ }^{6}$ [grifo nosso].

Essa busca pela regulação de dissidências se faz presente nas imagens-cena 1 e 2 . No primeiro caso, em uma performance-desabafo, o primeiro homem trans a realizar o procedimento de mastectomia no Mato Grosso do Sul relata que não desejava retirar seus seios, mas que realizou o procedimento por uma questão de reconhecimento social e, consequentemente, de acesso a direitos.

E no segundo caso, apesar de desejar a cirurgia, Skyler tem seu reconhecimento enquanto homem barrado pelo departamento de trânsito sob o argumento de que só seria referenciável como homem depois que estivesse "completo" - condição que dependia da retirada das mamas. Assim, o poder governamentaliza os corpos e sujeitos de modo a medir, controlar e corrigir aqueles que são lidos como anormais, em um disciplinamento dos corpos (FOUCAULT, 1999b) que busca incessantemente a coerência entre sexo, gênero, desejo e práticas sexuais (BUTLER, 2008).

Acrescenta-se que durante a entrevista, o profissional do hospital universitário relata a situação de primeira consulta de um homem trans que solicitou que, a princípio, fosse chamado no feminino, pois apesar de entender-se enquanto homem trans, ao olhar no espelho ainda via uma mulher cis, e então desejava ser chamado no masculino somente após a hormonioterapia fazer efeito. Apesar da impossibilidade de ter acesso ao usuário ${ }^{7}$, não podemos ignorar o fato de como seu cuidado de si estava intrinsecamente dependente da aprovação deste poder socialmente estabelecido e convencionalizado.

\footnotetext{
${ }^{6}$ Disponível em: http://portal.cfm.org.br/index.php?option=com content\&view=article\&id=28561:2020-01-0915-52-08\&catid=3 Acesso em 12/01/2020.

${ }^{7}$ Usuário nos termos do que preconiza as diretrizes do SUS.
} 


\section{Revista \\ Debates Insubmissos}

Neste contexto, a medicina torna-se um campo útil ao disciplinamento de corpos, dispondo de estratégias e tecnologias como as apresentadas na entrevista no ambulatório transexualizador: hormonioterapia e cirurgia para aumento ou retirada das mamas, redistribuição de gordura no corpo conferindo-lhe novo formato, enfim, uma "mudança praticamente completa de um corpo, desde genitália, desde mamas que podem ou não complementar". Trata-se, portanto, de uma "adequação" de um corpo entendido como ininteligível a um padrão binário (portanto, inteligível) - o que para o profissional levaria a uma maior passabilidade ${ }^{8}$.

Por outro lado, não se trata de uma via de mão única. Ao contrário, o investimento do corpo pelo poder possibilitou também o domínio e consciência do próprio corpo, em uma consequência direta houve a

Reivindicação de seu corpo contra o poder, da saúde contra a economia, do prazer
contra as normas morais da sexualidade, do casamento, do pudor. E assim, o que
tornava forte o poder passa a ser aquilo porque ele é atacado... O poder penetrou no
corpo, encontra-se exposto no próprio corpo (FOUCAULT, 2015, p. 235).

Assim, por mais pesada que seja a artilharia de guerra que busca docilizar, capturar e normalizar, a experiência dissidente subverte continuamente das técnicas de sujeição e gestão a partir das próprias fissuras e incoerências existentes no interior dos regimes de verdade (FOUCAULT, 1999a).

Uma dessas experiências dissidentes é a realizada por Ariel, situação apresentada na conversa 1, em que relata sua negociação entre saúde e a construção do corpo que deseja (no caso, o anseio pelo aumento dos seios). O novo hormônio era mais prejudicial para sua saúde, mas apresentava resultados mais rápidos. Em sua negociação com seu corpo e com os serviços disponibilizados pela medicina, a demora pesou mais, não aguentava mais a espera. Foi assim que chegou à conclusão de que sua construção corporal precisava acelerar. Num movimento de

\footnotetext{
${ }^{8}$ Termo êmico utilizado por pessoas travestis e trans para se referir às experiências de "passar por" (homem ou mulher). No âmbito acadêmico, a grande referência sobre a discussão de passabilidade é o trabalho de Tiago Duque (2017).
} 
cuidado de si que tensiona com os dispositivos docilizadores, um $\mathrm{CsO}$ não pode esperar. Antes tem pressa de produzir e assumir para si "a dor e a delícia de ser o que é". 9

Figura 1: Travesti e seus hormônios.

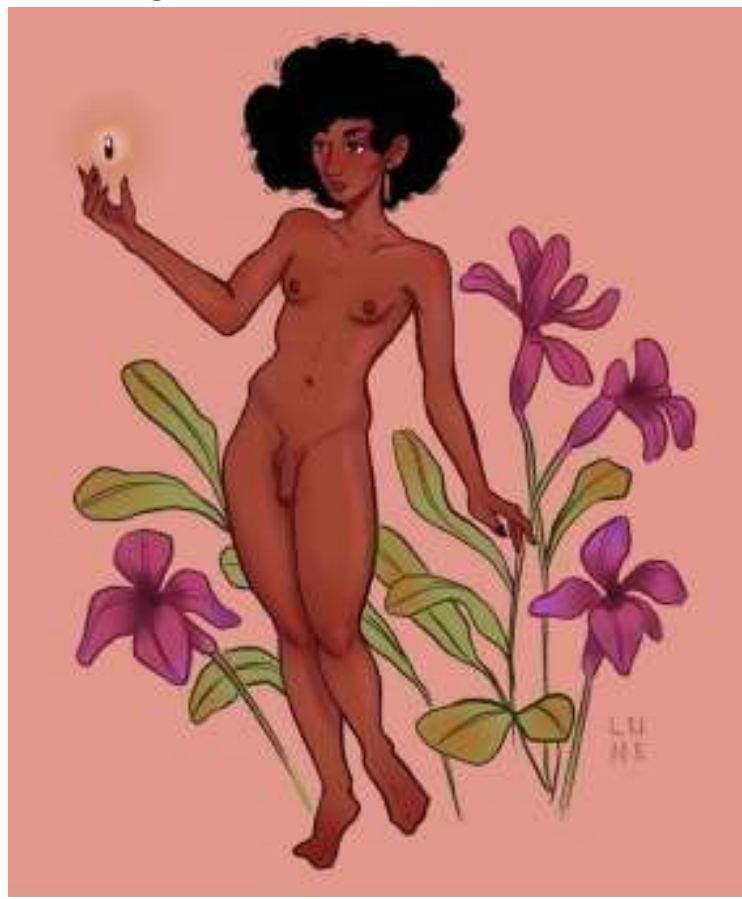

Créditos: Lune Carvalho. Disponível em: @lunecornio ${ }^{10}$.

Outras negociações com a saúde aparecem na entrevista realizada no ambulatório transexualizador, pelos relatos do profissional da saúde, algumas pessoas travestis e trans faziam uso de hormônios sem acompanhamento (frequentemente porque este acompanhamento era barrado por lei, em decorrência da faixa etária), ocorriam superdosagens, ou ainda o preenchimento do corpo com silicone industrial, em ambos os casos o médico alerta para os perigos de trombose, embolia, e até morte.

\footnotetext{
${ }^{9}$ Aludimos à música "Dom de Iludir” de autoria de Caetano Veloso.

${ }^{10}$ Esta versão foi posteriormente censurada no Instagram após inúmeras denúncias. Frente a isto, Lune repostou sua ilustração tampando partes do desenho, e na legenda posicionou-se contra tal censura, afirmando também que a ilustração original está disponível em seu site (https:/www.behance.net/gallery/87058219/Trans-WomanDigital-art). Por repudiarmos a censura aos corpos e falas dissidentes, apresentamos aqui a versão original, sem censuras.
} 


\section{Debates Insubmissos}

Revista

Uma experiência similar é narrada por Preciado (2018), o filósofo e seus amigos se autodenominam piratas do gênero ou hackers de gênero, considerando-se "usuários copyleft", ou seja, entendem "os hormônios sexuais como biocódigos livres e abertos cujo uso não deve estar regulado nem pelo Estado nem confiscado pelas companhias farmacêuticas" (PRECIADO, 2018, p. 59). No que diz respeito às dosagens, o autor questiona: "mas qual é a dose justa de testosterona? A que meu corpo produz? Ou outra? O que seria justiça hormonal? E se há justiça hormonal, eu deveria administrar essa justiça a mim mesmo?" (PRECIADO, 2018, p. 151).

É assim que lemos todo o movimento de autoadministração de hormônios (por exemplo, via anticoncepcionais) que algumas pessoas travestis e trans realizam à revelia do aparato biomédico. Nessa autoadministração transgressora, o que seria entendido dentro de uma ordem do discurso biomedicalizante restritivamente como "perigoso" passa a ser reivindicado como o direito de gerir e produzir o próprio corpo. Sim, um corpo plástico, um corpo anárquico, um $\mathrm{CsO}$ que é "perigosamente" 11 hormonizado. Aqui manifesta-se a possibilidade da construção de um corpo que lhe seja próprio, negociando sentidos outros, tecnologias (médicas também, por que não?), saúde e pronomes, em uma construção corporal à sua própria maneira, hora aproximando-se, hora afastando-se dos saberes hegemônicos e com eles disputando.

Na imagem-cena 3 (postagem do homem trans), "pedaços humanos" são negociados. Os seios causam incômodos, quem os porta preferiria não os ter. Todavia, este pedaço humano estava anexado ao seu corpo, até então sem a possibilidade de retirada. Para lidar com o que ele próprio elencou como "disforia", o uso de faixas comprimindo os seios, juntamente com roupas não apertadas, costumam ser tecnologias mais disponíveis, mas havia mais coisas que desejava para seu próprio corpo que não a compressão de uma faixa, desejava na verdade nada de faixas ou blusas, a liberdade de ficar sem camisa, de ser um homem sem camisa.

\footnotetext{
${ }^{11}$ Utilizamos o termo perigo/perigoso na contramão de um discurso moralizante. Inspirando-nos em Nietzsche, a experiência do perigo é aqui entendida como um contra-movimento, ou seja, todas aquelas experiências e experimentações que manifestam nossa vontade de potência à revelia dos mecanismos/sistemas/dispositivos opressores.
} 
Apesar do incômodo e de desejar que seus seios caíssem de seu corpo com a gravidade, decidiu que este pedaço humano preso em seu corpo não o impediria mais de fazer o que queria, os seios marcados em seu corpo não o impediriam de se afirmar homem, "sou homem, um homem com seios".

Figura 2: T r a n s Masculinidad e s [sic].

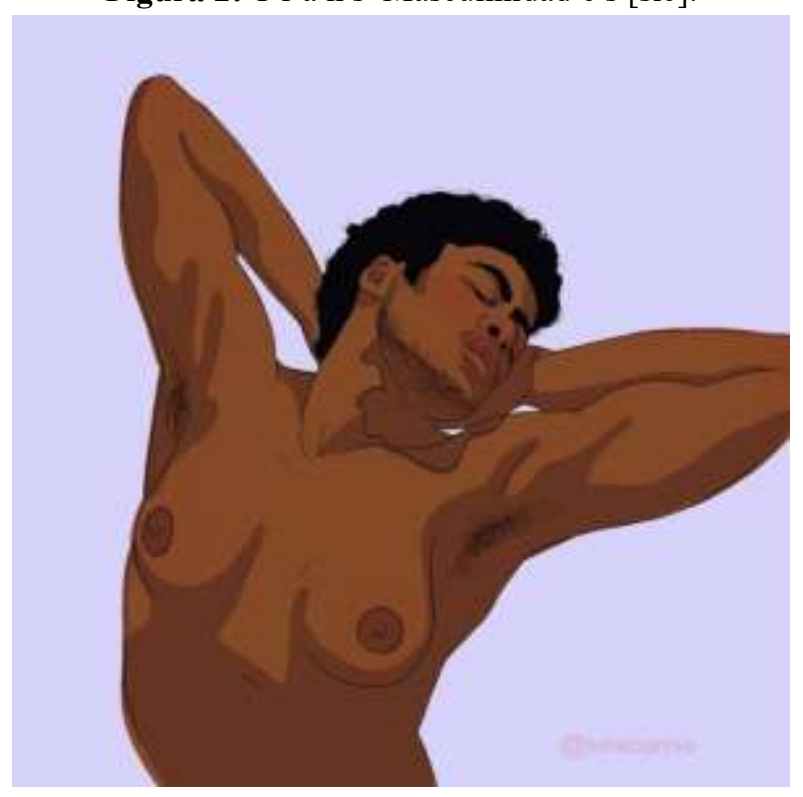

Em sua ausência, os seios também não impediram que a Miss Trans/Travesti 2019 do Mato Grosso do Sul se afirmasse como mulher. Emocionada e convicta a Miss sustenta que "não ter silicone não me faz menos mulher hoje" e a nota da organização do evento já dava o tom: ter à disposição silicone, plásticas e hormônios não é sinônimo de ser trans, pessoas cis também fazem uso, todavia a disponibilidade dessas tecnologias pode ser negociada e utilizada por cada pessoa para construir para si seu corpo trans, caso deseje. Tal situação aparece também em Laerte-se, e cabe dizer que "para além dos peitos, Laerte compreende que ser mulher é um desejo, um sentimento: o de se sentir mulher" (OLIVEIRA; MARTINS; NASCIMENTO, 2019, p. 119-120). 


\section{Debates Insubmissos}

Revista

Estas formas próprias de enxergar e construir um corpo são importantes processos de singularização, em que há a possibilidade de construção de referenciais próprios, viver seus processos e ler a própria situação, em um devir diferencial que recusa a subjetividade capitalística para produzir modos de subjetivação originais e singulares, sendo a criação sempre dissidente e transindividual (GUATTARI, ROLNIK, 2013). Para Guattari e Rolnik (2013, p. 58), os novos movimentos sociais dependem disso, estes "devem criar seus próprios modos de referência, suas próprias cartografias, devem inventar sua práxis de modo a fazer brechas no sistema de subjetividade dominante".

Do mesmo modo, para Foucault (1999a, p. 147), "contra o dispositivo de sexualidade, o ponto de apoio do contra-ataque não deve ser o sexo-desejo, mas os corpos e os prazeres". Nesse sentido, na construção de corpos dissidentes, a criação de um Corpo sem Órgão (CsO) nos parece particularmente potente ao produzir um processo de desterritorialização do corpo e desnaturalização do biológico. $\mathrm{O} \mathrm{CsO}$ "não é de modo algum o contrário dos órgãos. Seus inimigos não são os órgãos. $\mathrm{O}$ inimigo é o organismo. $\mathrm{O} \mathrm{CsO}$ não se opõe aos órgãos, mas a essa organização dos órgãos que se chama organismo" (DELEUZE; GUATTARI, 1996, p. 19), para qual o organismo está relacionado à acumulação e sedimentação, com imposição de formas e funções.

Aparenta haver então um paralelo entre a etnografia de Clastres (2007) e a ideia de Deleuze e Guattari (1996) de um corpo sem órgãos, de modo que Clastres (2007) investiga sociedades contra o Estado, e que, portanto, não ter Estado não se apresenta- como algo faltoso, mas uma oposição a este, firmando outros arranjos políticos. De modo similar, a ferramenta conceitual de Deleuze e Guattari (1996) pensa um corpo que é sem órgãos não por uma situação faltosa, mas por uma oposição pessoal e política contra a organização dominante destes, contra o organismo. O CsO se esvazia destas significâncias e subjetivações hegemônicas, "é feito de tal maneira que ele só pode ser ocupado, povoado por intensidades. Somente as intensidades passam e circulam” (DELEUZE; GUATTARI, 1996, p. 12).

Pessoas travestis e trans continuamente questionam o organismo, a organização generificada dos órgãos, a diferenciação sexual a partir de pedaços humanos e seus arranjos 


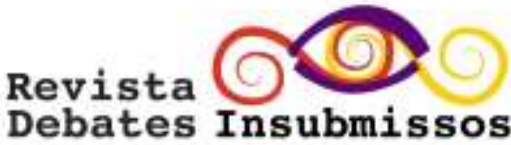

sedimentarizados, com isso, na construção de seus corpos e também em suas vivências, mesmo nas mais cotidianas, para qual "pouco importa a anatomia da genitália, e sim forjar para si uma materialidade desejante, um corpo protético" (OLIVEIRA; MARTINS; NASCIMENTO, 2019, p. 119), são potência de devir e de construção de um CsO.

Sua experimentação apresenta-se como possível em diversos relatos aqui trabalhados, para Deleuze e Guattari (1996, p. 9), “o CsO já está a caminho desde que o corpo se cansou dos órgãos e quer licenciá-los, ou antes, os perde" - experiência narrada pela pessoa da imagemcena 3, com o seu desejo que os seios caíssem do corpo com a gravidade, que estes fossem "perdidos".

Sobre CsO, os órgãos são distribuídos independentemente da forma do organismo, então “os órgãos perdem toda constância, quer se trate de sua localização ou de sua função (...) órgãos sexuais aparecem por todo o lado" (BURROUGHS, s.d., p. 21 apud DELEUZE; GUATTARI, 1996, p. 13). Neste sentido, e por considerar que a nomenclatura “órgãos sexuais" está atrelada a uma sofisticada tecnologia que prescreve o contexto de significação dos órgãos, a uma "tecnologia de dominação heterossocial que reduz o corpo a zonas erógenas em função da distribuição assimétrica do poder entre os gêneros (feminino/masculino), fazendo coincidir certos afetos com determinados órgãos" (PRECIADO, 2019, p. 414), propomos que substituamos a nomenclatura "órgãos sexuais" por "órgãos do prazer".

A ideia de órgãos do prazer, em substituição a nomenclatura hegemônica órgãos sexuais, abre o corpo a conexões múltiplas, em que o prazer não fica restrito a um órgão ou outro determinado pelo organismo e pela ciência, qualquer pedaço humano que lhe afete e gere a sensação de prazer, pode ser um órgão do prazer, experimentando o $\mathrm{CsO}$ ao esvaziar-se destes significantes dominantes e preencher a si mesmo com afetos e prazeres, desarticulando, ou ainda realizando articulações múltiplas, no qual os órgãos só aparecem e funcionam como intensidades puras, como um campo de imanência do desejo (DELEUZE; GUATTARI, 1996), para qual, "alguém que conseguiu finalmente, ter acesso a si próprio é, para si, um objeto de prazer" (FOUCAULT, 1985, p.70). 
Com isto, há a possibilidade de firmação de um contrato contrassexual, no qual "os corpos se reconhecem a si mesmos não como homens ou mulheres, e sim como corpos falantes, e reconhecem os outros corpos como falantes" (PRECIADO, 2019, p. 411), sendo uma teoria do corpo situada fora das oposições homem/mulher, masculino/feminino, heterossexualidade/homossexualidade.

Figura 3: Hormonização [sic].

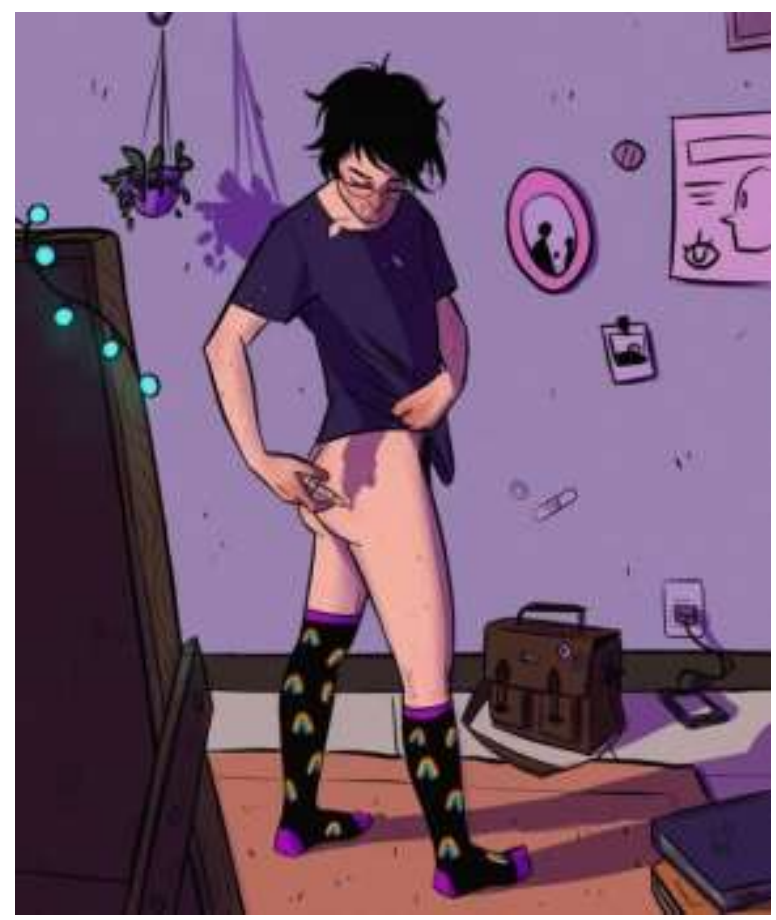

Créditos: Lune Carvalho. Disponível em: @lunecornio.

A experiência que a amiga de Ariel faz com os serviços médicos, através do acompanhamento hormonoterápico, de assimilação e incorporação de hormônios externos em seu corpo, aproxima-se de uma

Homeopatia política de gênero. Não se trata de passar de mulher para homem ou de homem para mulher, mas de contaminar as bases moleculares da produção da diferença sexual, entendendo que estes dois estados do ser, homem e mulher, existem apenas como "ficções políticas", como efeitos somáticos dos processos técnicos de normatização. Trata-se de uma questão de intervenção intencional neste processo de produção a fim de acabar com as formas viáveis de incorporação de gênero, de 
produzir uma nova plataforma sexual e afetiva que não é masculina nem feminina no sentido farmacopornográfico do termo (PRECIADO, 2018, p. 153).

Para Paul Preciado (2018), a aplicação de hormônios sem o desejo e projeto de transitar de uma ficção de sexo para outra, como o é experimentado pelo próprio autor e pela amiga de Ariel, seria nada além de um devir molecular, e acrescentamos: nesse linhamento de um devir molecular, há também a possibilidade de experimentações de $\mathrm{CsO}$ e de um contrato contrassexual.

Sendo esta construção corporal incessante, uma experiência de eterna tecnologia de produção, por vezes o corpo apresenta-se como incompleto, não porque lhe falte algo, mas por estar constantemente em mutação, confronta-se com o instável, precário, incerto, nãopredeterminado, contornos ambíguos, um corpo inconcluso, em movimento (LAURETIS, 1994 apud OLIVEIRA; MARTINS; NASCIMENTO, 2019).

\section{4. (IN)CONCLUSÕES FINAIS}

Nesta breve cartografia sobre como o saber médico por vezes se aproxima ou se afasta das estratégias elencadas pelos sujeitos em sua construção corporal, quisemos evidenciar que esse dispositivo normalizador não detém a última palavra. Assim, se alguns linhamentos mostraram a coerção que os sujeitos sofriam para adequarem seus corpos em grades de inteligibilidades binárias, em especial o caso relatado nas imagens-cena 1 e 2 e em partes da entrevista realizada no ambulatório transexualizador - a exemplo do caso do homem trans que tinha sua autorização de ser homem dependente da vontade de verdade biomédica -, em outros, como em linhas de fuga, a intensa produção de uma inteligibilidade dissidente que não se limita aos aparatos cisheteronormativizantes.

Desta forma, o que as diferentes imagens-narrativas aqui apresentadas nos mostram é a constante posição de suspeição a que os diferentes sujeitos produzem em relação às táticas disciplinares de vontade de verdade ao mesmo tempo em que se mostram incansáveis em suas estratégias de subversão e desautorização dos dispositivos normalizadores: como nos casos de auto aplicação hormonal, no uso de silicones industriais, nas lutas contra os pedaços humanos 


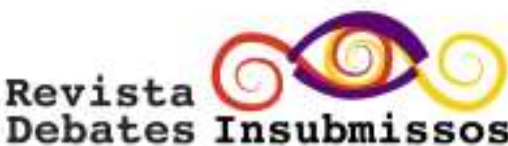

presos em seus corpos, na autoafirmação de uma identidade de gênero independente de uma estética corporal imposta, e até na construção de um $\mathrm{CsO}$ que funcione dentro de um contrato contrassexual - como apresentado nas imagens-cena 3 e 4, nas conversas 1 e 2 e também em alguns trechos da entrevista, em especial pela ideia do entrevistado de que a ajuda médica serviria apenas para auxiliar a mexer no invólucro e adequar o corpo ao formato em que a pessoa se sinta feliz.

Portanto, mais do que analisar a hegemonia (bio)médica, interessou-nos os múltiplos arranjos micropolíticos traçados pelas pessoas travestis e transsexuais em suas biocartografias de construção corporal. Ao percorrermos rizomaticamente instituições, imagens, trajetórias e narrativas, pudemos ter acesso a formas singulares, dinâmicas e criativas de produções de Corpos sem Órgãos.

Nesse movimento, onde nem tudo é o que parece, enquanto o aparato biomédico, a partir do dispositivo vontade de verdade, vê na "casca" uma verdade ontológica dos sujeitos, ao mesmo tempo que busca acessá-la incansavelmente, as experiências travestis e transsexuais falam e performam uma casca enquanto prótese de si. Próteses estas nunca prontas, nunca acabadas, em constante fazer-se e refazer-se, constituem-se como dinâmicas e criativas formas de experimentação, desejo e autodeterminação.

\section{REFERÊNCIAS}

BENEDETTI, Marcos Renato. Toda feita: o corpo e o gênero das travestis. Dissertação de Mestrado, Programa de Pós-Graduação em Antropologia Social, Universidade Federal do Rio Grande do Sul, Porto Alegre, 2000.

BUTLER, Judith. Corpos que pesam: sobre os limites discursivos do "sexo". Disponível em: https://territoriosdefilosofia.wordpress.com/2014/12/12/corpos-que-pesam-sobre-os-limitesdiscursivos-do-sexo-judith-butler/

BUTLER, Judith. Problemas de gênero: feminismo e subversão da identidade. 2a ed. Rio de Janeiro: Civilização Brasileira, 2008.

CLASTRES, Pierre, A sociedade contra o Estado: pesquisas de antropologia política. Tradução: Theo Santiago. São Paulo: UBU, 2007. 
DELEUZE, Gilles; GUATTARI, Félix. Mil Platôs: capitalismo e esquizofrenia - Vol. 3. Tradução de Aurélio Guerra neto. Rio de Janeiro: Editora 34, 1996.

DUQUE, Tiago. Gêneros Incríveis: um estudo sócio-antropológico sobre as experiências de (não) passar por homem e/ou mulher. Campo Grande: EDUFMS, 2017.

FOUCAULT, Michel. História da sexualidade I: a vontade de saber. 13 ed. Rio de Janeiro: Edições Graal, 1999a.

FOUCAULT, Michel. História da sexualidade III: o cuidado de si. Rio de Janeiro: Edições Graal, 1985.

FOUCAULT, Michel. Microfísica do poder. 2 ed. Rio de Janeiro: Paz e Terra, 2015.

FOUCAULT, Michel. Segurança, território, população: curso dado no Collège de France (1977-1978). São Paulo: Martins Fontes, 2008.

FOUCAULT, Michel. Vigiar e Punir: história da violência nas prisões. $20^{a}$ ed. Petrópolis: Editora Vozes, 1999b.

GUATTARI, Félix; ROLNIK, Suely. Micropolítica: cartografias do desejo. Petrópolis: Vozes, 2013, pp.33-146.

HARAWAY, Donna. Manifesto ciborgue: ciência, tecnologia e feminismo-socialista no final do século XX. In: TADEU, Tomaz (Org.). Antropologia do ciborgue: As vertigens do póshumano. 2 ed. Belo Horizonte: Autêntica, 2009.

LEITE JR, Jorge. Nossos corpos também mudam: a invenção das categorias "travesti" e "transexual" no discurso científico. São Paulo: Annablume/FAPESP, 2011.

NEER, Anahí Farji. Reconfiguraciones del rol de la psicoterapia en el marco de los tratamientos de construcción corporal trans (Argentina, 1997-2017). In: BRAZ, Camilo; HENNING, Carlos Eduardo (Orgs.). (2017). Gênero, sexualidade e saúde: Diálogos latino-americanos. Goiânia: Editora da Imprensa Universitária.

OLIVEIRA, Esmael Alves de; MARTINS, Catia Paranhos; NASCIMENTO, Letícia Carolina Pereira do. "Laerte-se" e "Tomboy": convites às experimentações de si. Ambivalências, v.7, n.13, p. 109 - 126, Jan-Jun/2019.

PRECIADO, Paul B. O que é a contrassexualidade? In: HOLLANDA, Heloisa Buarque de (Org). Pensamento feminista: conceitos fundamentais. Rio de Janeiro: Bazar do Tempo, 2019.

PRECIADO, Paul Beatriz. Testo junkie: sexo, drogas e biopolítica na era farmacopornográfica. Traduzido por Maria Paula Gurgel Ribeiro. São Paulo: n-1 edições, 2018.

TADEU, Tomaz. Nós, ciborgues: O corpo elétrico e a dissolução do humano. In: TADEU, Tomaz (Org.). Antropologia do ciborgue: As vertigens do pós-humano. 2 ed. Belo Horizonte: Autêntica, 2009.

VIEIRA, Leonardo Triandopolis. Pedaços humanos. Campo Grande: Não Sou Uma Editora, 2017. 
Revista

Debates Insubmissos

Submetido: $30 / 01 / 2020$

Aprovado: 16/07/2020

REVISTA DEBATES INSUBMISSOS, Caruaru, PE. Brasil, Ano 4, v.4, no 13, mai./ago. 2021. ISSN: 2595-2803

Endereço: https://periodicos.ufpe.br/revistas/debatesinsubmissos/ 